\title{
Analysis of Pyridine, Picoline and Lutidine's Adsorption Behavior on The Al (111)-lattice
}

\author{
Fatemeh Mollaamin ${ }^{1,2 * \mathbb{D}}$, Fatma Kandemirli ${ }^{1}{ }^{\mathbb{D}}$, Majid Monajjemi ${ }^{2}$ (D) \\ 1 Department of Biomedical Engineering, Faculty of Engineering and Architecture, Kastamonu University, Kastamonu, \\ Turkey \\ 2 Department of Chemical engineering, Central Tehran Branch, Islamic Azad University, Tehran, Iran \\ * Correspondence: smollaamin@gmail.com (F.M.);
}

Scopus Author ID 35848813100

Received: 18.06.2021; Revised: 22.07.2021; Accepted: 27.08.2021; Published: 8.08.2021

\begin{abstract}
The reactivity and adsorption behavior of five organic inhibitors of pyridine and its derivatives of 2-picoline, 3-picoline, 4-picoline, and 2,4-lutidine at the $\mathrm{Al}(111)$ lattice in hydrochloric acid was studied by the principle of the HF and B3LYP level using the 6-31G and LANL2DZ basis sets from the program package gaussian 03 . The compound was adsorbed on the metal lattice based on the calculated results, mainly in their protonated forms. In the $\mathrm{Al}$ (111)-lattice, the charge is transferred to the inhibitor, and the organic inhibitor is adsorbed at the $\mathrm{Al}$ (111)-lattice in an inclined state. The quantum chemical calculations of molecular reactivity show that the frontier orbitals of the four additives are distributed around the nitrogen atom of the pyridine ring, the aluminum atom of $\mathrm{Al}$ (111)lattice, and active electrophilic centers are located on the nitrogen atoms of the pyridine ring. All five molecules were adsorbed with the chemical adsorption on the $\mathrm{Al}$ (111)-lattice, and the order of adsorption was 2-picoline>2, 4-lutidine> 4-picoline> 3-picoline> pyridine. The $\mathrm{N}$ atoms of four derivatives form $\mathrm{N}$-Al bonds with the $\mathrm{Al}$ atoms of the $\mathrm{Al}$ (111)-lattice, which makes derivatives stably adsorb on the Al lattice.
\end{abstract}

Keywords: Al (111)-lattice; corrosion inhibition; pyridine; picoline and lutidine; adsorption.

(c) 2021 by the authors. This article is an open-access article distributed under the terms and conditions of the Creative Commons Attribution (CC BY) license (https://creativecommons.org/licenses/by/4.0/).

\section{Introduction}

Recently, the inhibition efficiency depends on the parameters of the system: metal composition, $\mathrm{pH}$, and structure of inhibitor molecule (Scheme 1). Inevitably, heterocyclic structures, including nitrogens, are corrosion inhibitors for some metal surfaces in different acidic environments [1-11]. For instance, the compounds of benzotriazole at the copper and iron surface [12-15], derived isoquinoline, and imidazole [16, 17] at the iron surface are efficient inhibitors for corrosion of these compounds [1-17].

Recently, it was studied that pyridine and its derivatives had been applied as corrosion inhibitors of the aluminum electrode [18, 19]. The researchers investigated the corrosion inhibition of aluminum electrodes with the pyridine and its derivatives by means of a basic quantum chemical method (MNDO) [20]. In this article, it has been debated the impact of organic inhibitors of pyridine and its derivatives of 2-picoline, 3-picoline, 4-picoline, and 2, 4lutidine on the inhibition of $\mathrm{Al}$ (111) lattice in $\mathrm{HCl}$ media using the quantum mechanical method of Hartree-Fock and density functional theory by B3LYP basis set. The electronic 
structure of the organic inhibitors has a key effect on the efficiency of metal corrosion inhibition.
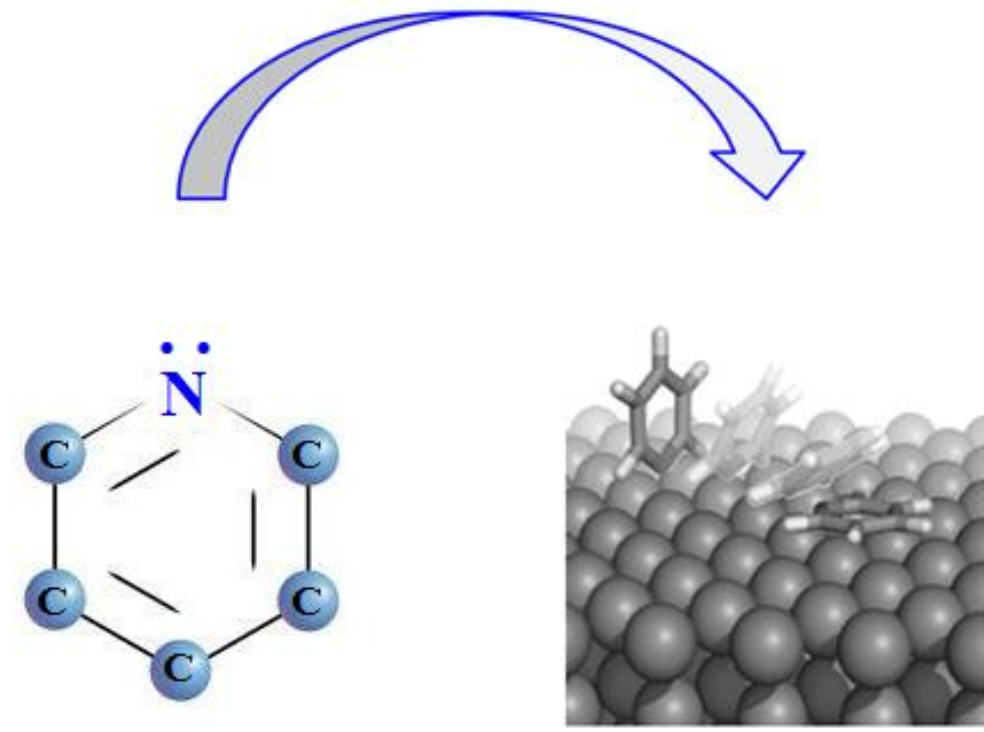

Scheme 1. Adsorption of inhibitors on the metal composition depending on $\mathrm{pH}$ and structure of inhibitor molecule.

Commonly, aluminum alloys and aluminum are applied in the fields of automobile manufacturing, national defense industry, aviation industry, electronics, and important daily manufacturing with their perfect properties [21, 22]. In fact, aluminum is produced by the HallHéroult method with high energy consumption, serious equipment corrosion, environmental pollution, etc. $[23,24]$.

It is necessary to explore a low-temperature green production method of aluminum, and it is also a research turning point in this field. Recently, magnificent development has been seen in low-temperature aluminum electrolysis. It has been focused on the replacement of the cryolite molten salt system by the molten salt system with lower melting points like chloride/fluoride. The electrolysis temperature can be reduced to a certain extent bt these strategies [22-24]. The ionic liquids are prepared for the progress of low temperature in aluminum electrolysis methodology.

In some studies, an ionic system has been discovered composing some inorganic or organic anions and organic cations and is liquid at or near room temperature [25-28].

In fact, non-volatile, electrochemical parameters, temperature range, stability, and conductivity properties are largely applied in different fields such as electrochemistry, catalysis, organic synthesis, extraction, and separation [25-36].

In recent years, as a new type of green electrolyte, ionic liquids have been used for aluminum electrodeposition and electrolysis refining at or near room temperature, and some development has been made [29-34]. Nevertheless, some problems are still to be solved, such as high electrolyte viscosity and dendrite phenomenon in the deposition layer [31-34]. The addition of additives is one of the common methods to address these problems $[35,36]$.

Recently, some developments have been done with the effects of some aromatic compounds on the electrodeposition of aluminum in ionic liquids [37-40].

The influence of methyl carbonate on electrodeposition of aluminum in $[\mathrm{EMIM}] \mathrm{Cl} / \mathrm{AlCl}_{3}$ system by cyclic voltammetry has been studied [41]. It has been explored that Nano Al could be prepared by adding nicotinic acid into [EMIM] $\mathrm{Cl} / \mathrm{AlCl}_{3}[42,43]$. 


\section{Materials and Methods}

With the development of computational techniques, an operative key has recently explored the reaction paths of structures. People can study the reaction activity, electron transfer, structure-activity relationship by calculating the Fukui index, charge distribution of heavy atoms, and the other quantum chemical parameters. The interaction between structures can be shown from the quantum chemical factors preparing a sufficient way to study adsorption mechanisms among molecules and interfaces at different levels. It has been used to the discovery of different metals lattice properties [44-46]. Valencia et al. studied the adsorption mechanism of [EMIM] $\mathrm{BF}_{4}$ on the Li (100) lattice with DFT (density functional theory ), and explored that pouring a small value of [EMIM]BF4 to Li-ion battery can inhibit dendritic existence and develop battery action [44,45]. Clarke et al. studied the effect of [EtNH 3$] \mathrm{BF}_{4}$ on the Li-ion battery system by DFT and molecular dynamics simulation (MD). These works provide a new way to explore the interaction mechanism between additives and metal lattices in ionic liquids [46].

As a kind of ring compound with delocalized bonds, aromatic compounds are applied in electrolysis with a stable formula and hard analysis. Derivatives of pyridine have been applied because of their strong decomposition and limit of their ability in liquid media. In fact, Nicotinamide, Pyridine-2-formamide, and Pyridine-4-formamide can be applied as sufficient agents for electrodeposition of $\mathrm{Al}$ in [Bmim] $\mathrm{Cl} / \mathrm{AlCl} 3$ [47]. The data indicated that the displacement was Nicotinamide> Pyridine-2-formamide> Pyridine-4-formamide. The way is uncertain, particularly the interaction between additives and electrode, charge transfer, and adsorption phenomenon. Because of the chemical elements and low hydrogen evolution overpotential, platinum has a very important application in electrochemistry, such as an auxiliary electrode, modified electrode substrate, electro-catalysis, etc.

A platinum electrode is commonly used to measure electrochemical properties of a water media, molten salt, electrolyte of organic compounds, and ionic liquid, like cyclic voltammetry, polarization graph, and electrochemical measurement. It is significant to learn the adsorption of structures on the surface of the Pt atoms, which have the best catalytic action applying like a catalyst in the fuel cell, petrochemical industry, automobile exhaust purification, and other fields (Scheme 2) [48].

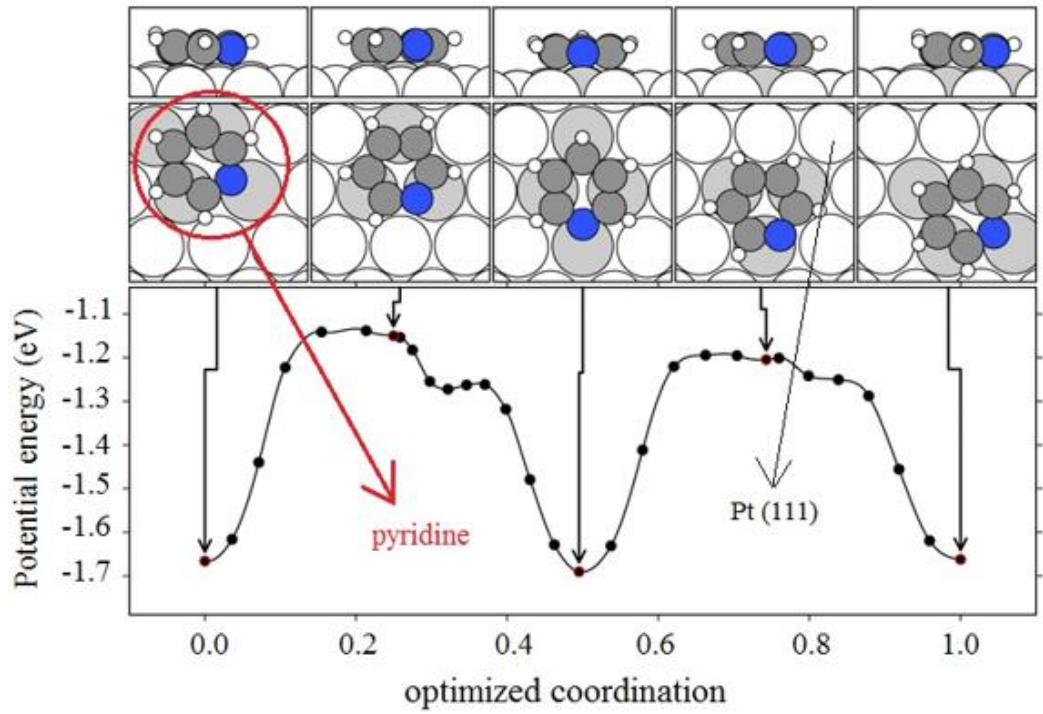

Scheme 2. Pyridine adsorption and diffusion on Pt (111) investigated with density functional theory. 
In this paper, the interaction mechanism of pyridine and its derivatives of 2-picoline, 3picoline, 4-picoline, and 2, 4-lutidine with $\mathrm{Al}$ (111)-lattice was studied by the First Principles method. The reactivity and adsorption behavior of the five compounds on the $\mathrm{Al}$ (111)-lattice were analyzed, and the interaction mechanism of pyridine amide derivatives on the $\mathrm{Al}$ (111)lattice was revealed to provide a theoretical reference and guidance for electrodeposition of aluminum in ionic liquids. All calculations have been carried out using the HF and B3LYP method and the 6-31G and LANL2DZ basis sets from the program package gaussian 03 [49].

For each of the crystal systems, there is, in principle, an infinite number of the possible lattice that can be exposed. The interval of the closest approach of atoms is $0.28630 \mathrm{~nm}$ [50]. In this model, we use the $\mathrm{Al}$ (111) - lattice formed by the crystal plane of $\mathrm{Al}$ atoms (Figure 1).

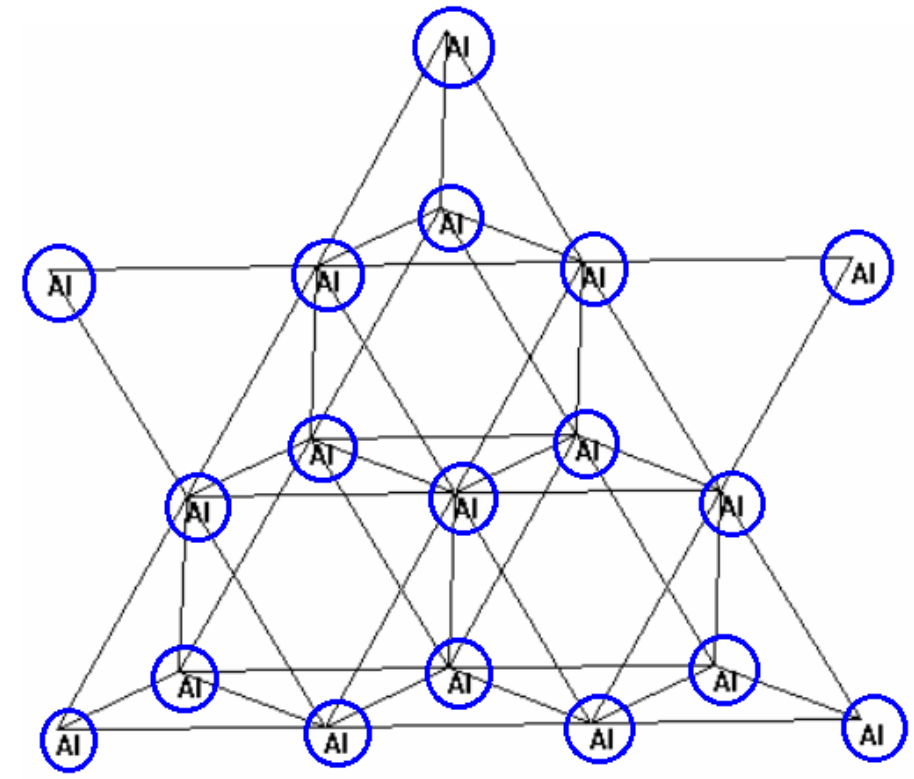

Figure 1. Two layers of Al-surface formed by aluminum atoms on (111) crystal plane.

Pyridine, $\mathrm{C}_{5} \mathrm{H}_{5} \mathrm{~N}$, is a mixed heterocyclic compound containing one nitrogen atom. The homologs of pyridine are commonly called pyridine bases. So, pyridine can be mixed at all rates with water and the most common organic solvents with a boiling point of $35^{\circ} \mathrm{C}$ higher than benzene. Some important compounds include pyridine,2-methypyridine(2- picoline),3methypyridine(3-picoline),4-methypyridine(4-picoline),2,4-dimethypyridine(2,4lutidine)(Figure 2) [50].<smiles>c1ccncc1</smiles>

(a)<smiles>Cc1ccccn1</smiles>

(b)<smiles>Cc1cccnc1</smiles>

(c)<smiles>Cc1ccncc1</smiles>

(d)<smiles>Cc1ccnc(C)c1</smiles>

(e)

Figure2. (a) Pyridine and four derivatives including (b) 2-picoline, (c) 3-picoline, (d) 4-picoline, (e) 2, 4lutidine.

Then the adsorption model of pyridine and its derivatives on the $\mathrm{Al}$ (111)-lattice have been optimized by gaussian 03 (Figure 3). 


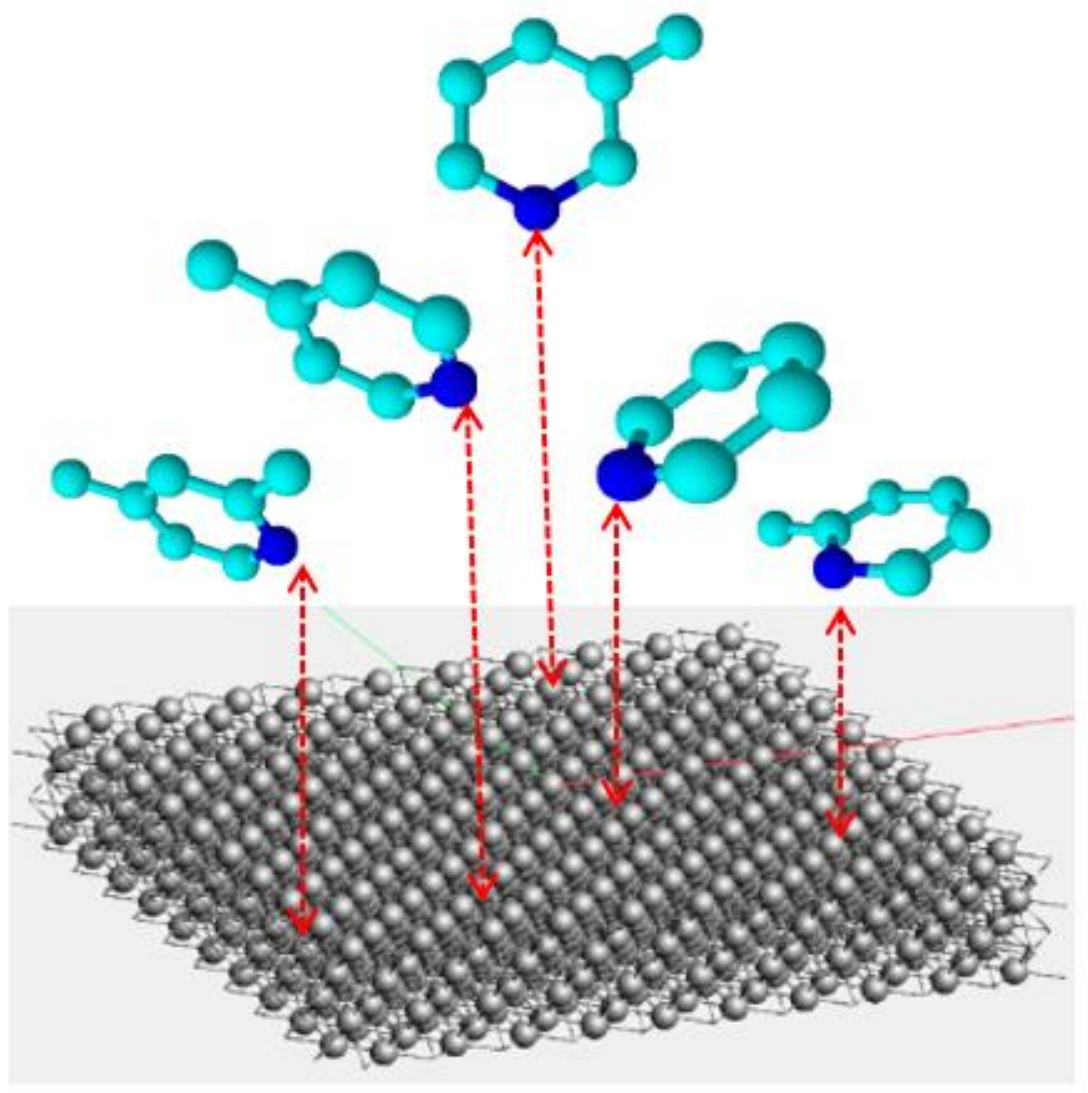

Figure 3. Al (111) - lattice formed by crystal plane of $\mathrm{Al}$ atoms adsorbed by pyridine and its derivatives.

The stabilization Energy, Es, is given as:

$$
\begin{aligned}
& E_{s}=E_{p}-E_{r} \\
& E_{s}^{+}=E_{p}{ }^{+}-E_{r}^{+}
\end{aligned}
$$

where $\mathrm{E}_{\mathrm{p}}$ represents the total energy of the given adsorption model consisting of nonprotonated pyridine by its derivatives and the $\mathrm{Al}$ (111)-lattice, $\mathrm{E}_{\mathrm{r}}$ is the sum of the total energy of the free non-protonated molecule of the inhibitor and the energy of the $\mathrm{Al}(111)$ - lattice without interaction. Besides, $\mathrm{E}_{\mathrm{s}}{ }^{+}$show the protonated stabilization Energy with $\mathrm{E}_{\mathrm{p}}$ represents the total energy of the given adsorption model consisting of protonated pyridine by its derivatives, and the $\mathrm{Al}$ (111)-lattice, Er is the total energy of the protonated complex of the inhibitor and the energy of the aluminum- surface.

Other theoretical elements consist of the electronic charge $(\mathrm{Q})$, the change value of the electronic charge of the $-\mathrm{NH}+$ part in the pyridine cycle $(\Delta \mathrm{Q} \mathrm{NH}+)$, the changes of the electronic charge of the aluminum - lattice ( $\Delta \mathrm{Q}$ Al(111)- lattice), the adsorption distance $(\mathrm{R})$, adsorption angle (A), and the adsorption dihedral angle (D).

\section{Results and Discussion}

Some inhibitor materials like phosphates, silicates, nitrates, nitrites, benzoates, Nheterocyclic compounds, and others influence the reaction in the cathode. Inhibitor materials of this forme have been applied in the water media [50].

Inhibitor materials usually only decrease corrosion, but sometimes such as $\mathrm{H} 2 \mathrm{O}$ groups proper, inhibition can prevent the corrosion. A surface does this action through the reactions of anode or cathode. Chromate prevents the reactions of the anode by using chromate conversion 
coatings as an inhibitor for Al-surfaces. If anodic inhibitors are not enough, they may prevent the corrosion to limited positions and multiply the corrosion at other localized positions.

In fact, in this research, the electronic foundation of substances of the inhibitor and the Al-aluminum lattice is important. The efficiency of an organic inhibitor of metallic corrosion depends on the structure of the inhibitor molecule and properties of the medium on the nature of the metal and the other experimental situations. With these experimental situations, the electronic foundation of the organic molecule of inhibitors has a principal impact on the yield of corrosion of the metal.

In this model, inhibitor molecules of pyridine and four derivatives, including 2-picoline, 3-picoline, 4-picoline, and 2,4-lutidine have been adsorbed at the Al(111)- lattice in an inclined state (Figure 3). We found the distance between $\mathrm{N}$ atom in the pyridine ring and the $\mathrm{Al}$ atom in the $\mathrm{Al}(111)-$ lattice [51].

\subsection{Non-protonated pyridine and its derivatives.}

Table 1 has shown that the corrosion inhibition efficiencies might relate to the stabilization energies (Es) (Figure 4). The simple regressions are obtained with the inhibition efficiencies $(\eta)$ and the change value of the net charge of the $-\mathrm{N}$ group in the pyridine ring and four derivatives $\left(\Delta \mathbf{Q}_{\mathbf{N}}\right)$ of 2-picoline, 3-picoline, 4-picoline, and 2,4-lutidine (Table 1). The linear regression shows the following relationships (Figure5):

$$
\boldsymbol{\eta}=-3387.9 \Delta \mathbf{Q}_{\mathbf{N}}-1199.8 \quad, \quad \mathrm{R}^{2}=0.7072
$$

Table 1. The calculated parameters of non-protonated pyridine and its derivatives.

\begin{tabular}{|c|c|c|c|c|c|c|c|}
\hline Inhibitor & $\mathbf{R}_{\mathbf{N}-\mathbf{A l}(\mathbf{1})}(\AA)$ & 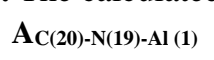 & 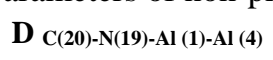 & $\mathrm{ES}_{S}(\mathrm{kcal} / \mathrm{mol})$ & $\Delta \mathbf{Q N}_{\mathbf{N}}(\mathbf{e})$ & $\Delta \mathbf{Q}$ Al- lattice $(\mathbf{e})$ & $\eta$ \\
\hline Pyridine & 1.78 & 88.89 & -11.89 & -19.94 & -0.36 & 0.57 & 20.80 \\
\hline 2-Picoline & 1.79 & 146.51 & -32.20 & -25.33 & -0.38 & 0.54 & 65.65 \\
\hline 3-Picoline & 1.78 & 142.89 & 84.93 & -18.91 & -0.37 & 0.55 & 60.00 \\
\hline 4-Picoline & 1.77 & 144.24 & 15.17 & -19.48 & -0.37 & 0.62 & 67.43 \\
\hline 2,4-Lutidine & 1.79 & 149.02 & 91.52 & -22.82 & -0.38 & 0.56 & 99.00 \\
\hline
\end{tabular}

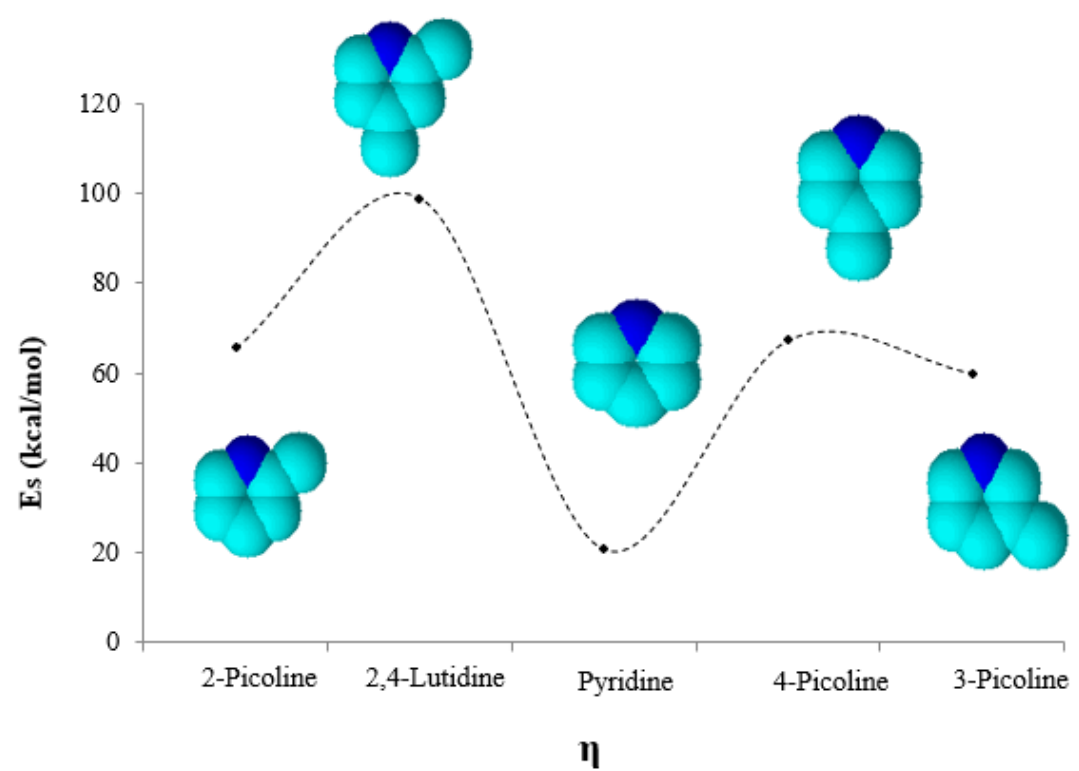

Figure 4. Calculated stabilization energies (Es) versus inhibition efficiencies $(\eta)$ on the non-protonated pyridine and four derivatives of 2-picoline, 3-picoline, 4-picoline, and 2,4-lutidine. 


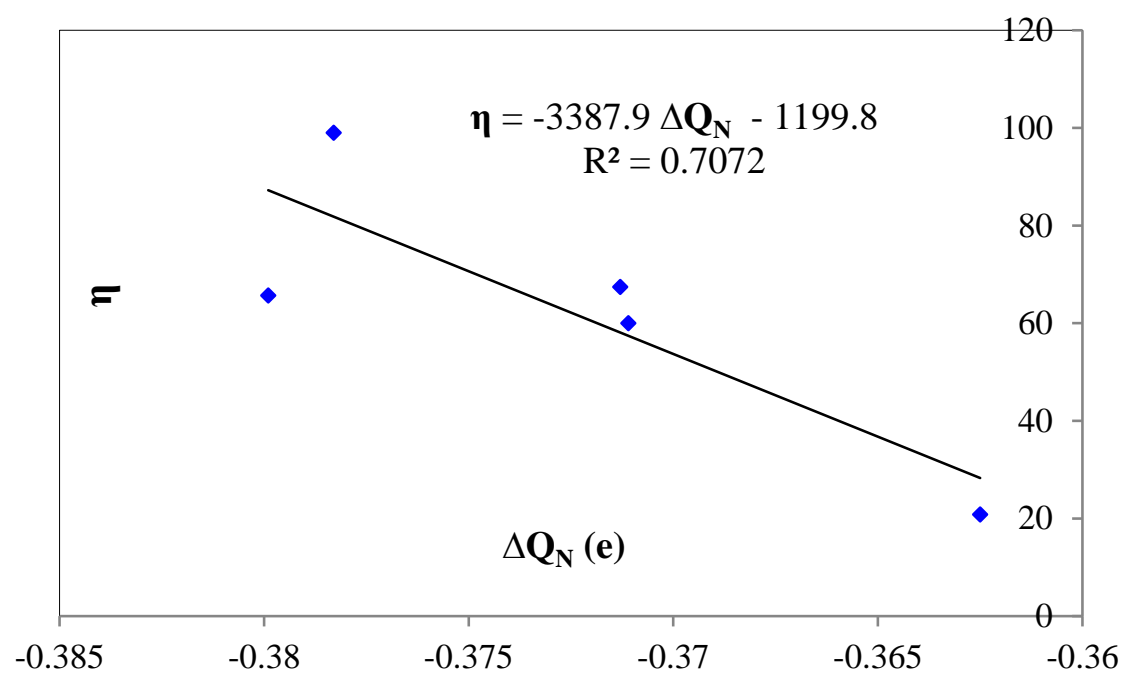

Figure 5. The linear regression of inhibition efficiencies $(\eta)$ versus the net charge of the $-\mathrm{N}$ group $\left(\Delta \mathbf{Q}_{\mathrm{N}}\right)$ in the pyridine ring and four derivatives of 2-picoline, 3-picoline, 4-picoline, and 2,4-lutidine.

\subsection{Protonated pyridine and its derivatives.}

It has been modeled the pyridine and four derivatives of 2-picoline, 3-picoline, 4picoline, and 2,4-lutidine as protonated compounds in hydrochloric acid $(\mathrm{HCl})$ as weak bases (Figure 6). According to the values in Table 2, the charge changes of $-\mathrm{NH}+$ group $\left(\Delta \mathbf{Q}_{\mathrm{NH}^{+}}{ }^{+}\right)$of the protonated pyridine and four derivatives of 2-picoline, 3-picoline, 4-picoline, and 2,4lutidine have been valued as the simple regression as follows (Figure 7):

$$
\Delta \mathrm{QNH}_{+}=865.94 \mathrm{Es}^{+}+227.15 \quad, \quad \mathrm{R}^{2}=0.6245
$$
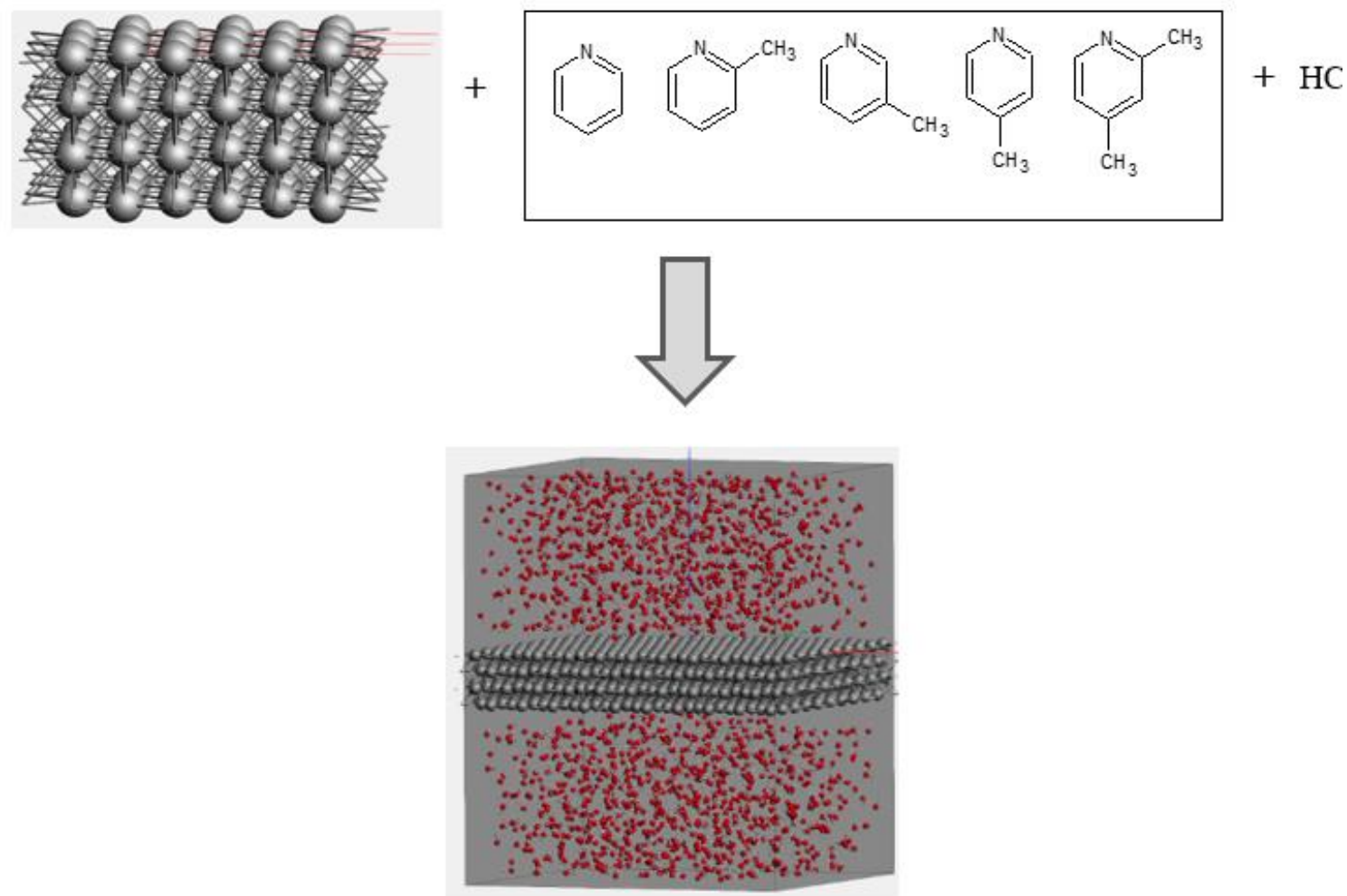

Figure 6. Protonated Pyridine and four derivatives of 2-picoline, 3-picoline, 4-picoline and 2,4-lutidine in $\mathrm{HCl}$. 
Table 2. The calculated parameters of protonated pyridine and its derivatives in hydrochloric acid $(\mathrm{HCl})$.

\begin{tabular}{|c|c|c|c|c|c|c|}
\hline Inhibitor & $\mathbf{R}_{\mathbf{N}-\mathbf{A l}(\mathbf{1})}(\AA)$ & 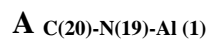 & $D_{C(20)-N(19)-A l(1)-A l(4)}$ & $\mathrm{Es}^{+}(\mathrm{kcal} / \mathrm{mol})$ & $\Delta \mathbf{Q}_{\mathrm{NH}+}(\mathbf{e})$ & $\Delta \mathbf{Q}_{\mathrm{Al} \text { - lattice }}(\mathbf{e})$ \\
\hline Pyridine & 1.91 & 86.75 & -10.96 & -53.60 & -0.32 & 1.11 \\
\hline 2-Picoline & 1.95 & 132.56 & -54.33 & -43.31 & -0.31 & 1.08 \\
\hline 3-Picoline & 1.92 & 127.13 & 59.63 & -45.52 & -0.32 & 1.09 \\
\hline 4-Picoline & 1.92 & 126.51 & -7.80 & -42.85 & -0.30 & 1.07 \\
\hline 2,4-Lutidine & 1.96 & 134.34 & 63.17 & -31.57 & -0.30 & 1.04 \\
\hline
\end{tabular}

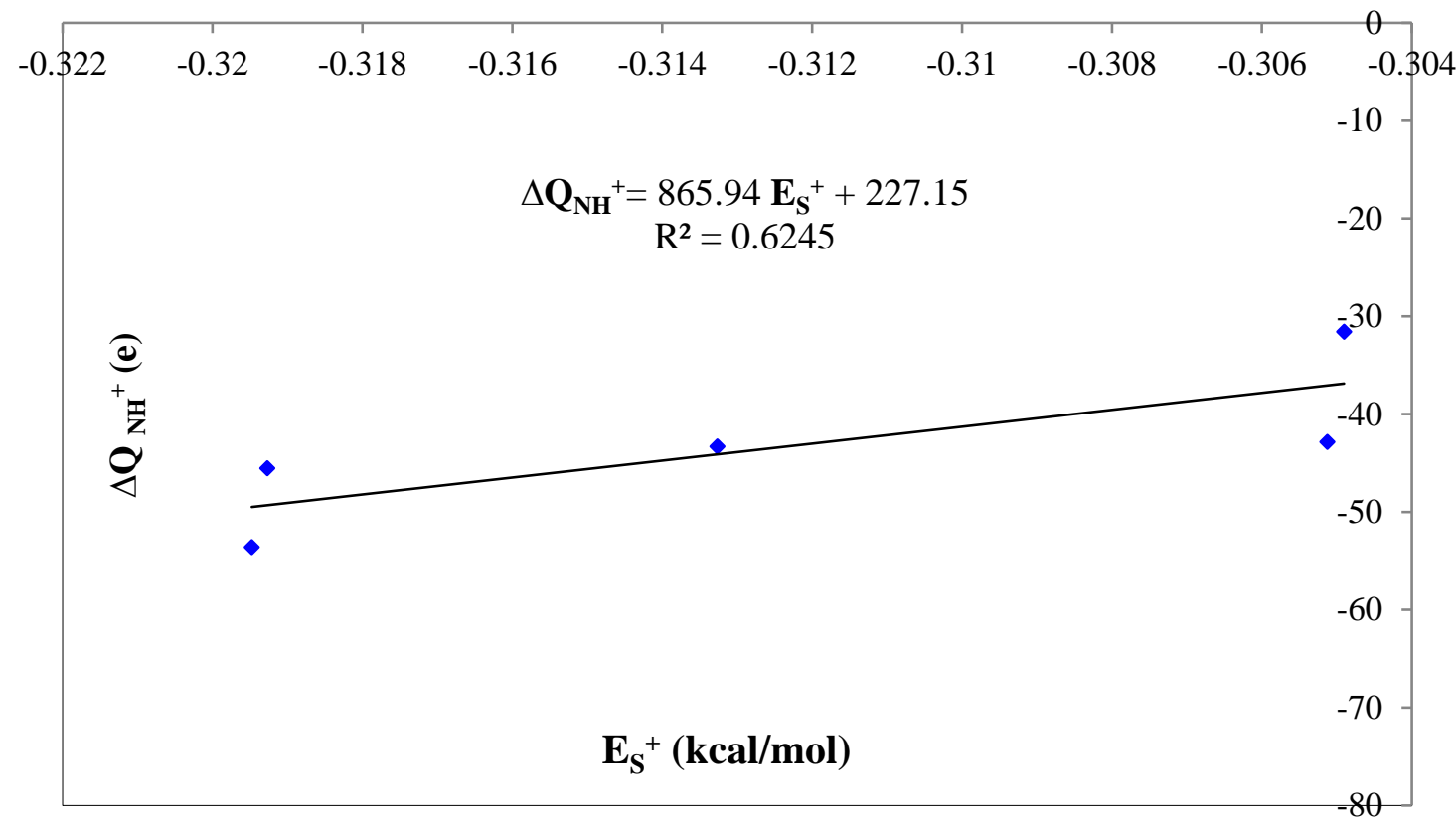

Figure 7.The charge changes of $-\mathrm{NH}^{+}$group $\left(\Delta \mathbf{Q N H}^{+}\right)$of the protonated pyridine and four derivatives of 2picoline, 3-picoline, 4-picoline, and 2,4-lutidine versus protonated stability energy $\left(\mathrm{E}_{\mathrm{S}}{ }^{+} \mathrm{kcal} / \mathrm{mol}\right)$.

Because the $-\mathrm{NH}^{+}$group of the protonated pyridine ring has a positive charge, it accepts the electron of the aluminum atoms easily; that is, it is an electron acceptor. The charge of the $\mathrm{Al}$ (111)-lattice is affected and turns positive by the adsorption, so the electronic transfer may be from the $\mathrm{Al}$ atom to the organic inhibitor through the frontier orbital of the interface when the inhibitor is adsorbed on the $\mathrm{Al}$ (111)-lattice (Figure 7).

The $\mathrm{N}-\mathrm{Al}$ adsorption distance has been obtained from the optimization calculations (Table 2). These results show that the $\mathrm{N}-\mathrm{Al}$ covalent bond between the inhibitor and the $\mathrm{Al}$ (111)-lattice has been formed.

Based on equation 2, Ep represents the total energy of the given adsorption model consisted of protonated pyridine derivatives and the $\mathrm{Al}(111)$ - lattice, Er is the sum of the total energy of the free protonated molecule of the inhibitor and the total energy of the $\mathrm{Al}$ (111)lattice without interaction.

$\Delta \mathrm{Q}_{\mathrm{NH}^{+}}{ }^{+}$represents the change value of the net charge of the $-\mathrm{NH}^{+}$group in the pyridine ring. $\Delta \mathrm{QNH}^{+}=\mathrm{Q}^{\prime} \mathrm{NH}^{+}-\mathrm{QNH}^{+}$; $\mathrm{Q}^{\prime} \mathrm{NH}^{+}$is the charge of the $-\mathrm{NH}^{+}$group when the inhibitor is adsorbed on the $\mathrm{Al}$ (111)-lattice, $\mathrm{QNH}^{+}\left(=\mathrm{Q}_{\mathrm{N}}+\mathrm{QH}^{+}\right)$is the net charge of the $-\mathrm{NH}^{+}$group of the protonated pyridine and its derivatives (Figures 6,7).

\subsection{Co-adsorption modeling with a hydrogen atom and $\mathrm{Cl}^{-}$anion in acidic media.}

The key factor of their inhibition properties is their electronic and molecular structure characteristics but not their molecular areas. The results optimized by the HF method show that 
they can be adsorbed on the $\mathrm{Al}(111)$ - lattice in the inclined states, and the inclined angles of the inhibitors adsorbed on the $\mathrm{Al}(111)$ - lattice.

The Al (111)-lattice with one hydrogen and one $\mathrm{Cl}^{-}$was used as the substrate for modeling the co-adsorption (Figure 8). The results of the optimized calculation are shown in Table 3.

Table 3. The quantum mechanical calculated of co-adsorption model with a hydrogen atom and $\mathrm{Cl}^{-}$anion.

\begin{tabular}{c|c|c|c|c|c|c} 
Pyridine & 1.90 & 88.22 & -8.21 & 1.42 & 2.09 & -385.25 \\
\hline 2-Picoline & 1.94 & 134.27 & -43.39 & 1.41 & 2.09 & -374.51 \\
\hline 3-Picoline & 1.90 & 128.13 & 47.54 & 1.42 & 2.08 & -371.84 \\
\hline 4-Picoline & 1.91 & 127.80 & 1.41 & 1.42 & 2.09 & -371.78 \\
\hline 2,4-Lutidine & 1.95 & 137.27 & 43.75 & 1.42 & 2.08 & -355.60 \\
\hline \multicolumn{6}{c}{$\mathrm{E}_{\mathrm{s}}=\mathrm{E}_{\mathrm{Al}(111)-\text { lattice }+\mathrm{H}+\mathrm{Cl}^{-} \text {+inhibitor }}\left(\mathrm{E}_{\mathrm{Al}(111)-\text { lattice }}+\mathrm{E}_{\mathrm{H}}+\mathrm{E}_{\mathrm{Cl}}{ }^{-}+\mathrm{E}_{\text {inhibitor }}\right)$}
\end{tabular}

Comparing Table 3 to 2, we can find the stabilization energy increases. It may be the adsorption of Cl-that causes the increase of the negative charge on the $\mathrm{Al}$ (111)-lattice, which improves the interaction between protonated pyridine and the Al (111)-lattice. We can conclude that the adsorption of the inhibitor is possible only at a lattice partially covered with hydrogen and $\mathrm{Cl}^{-}$. It is now clear why pyridine and its derivatives can act as an inhibitor of aluminum corrosion.

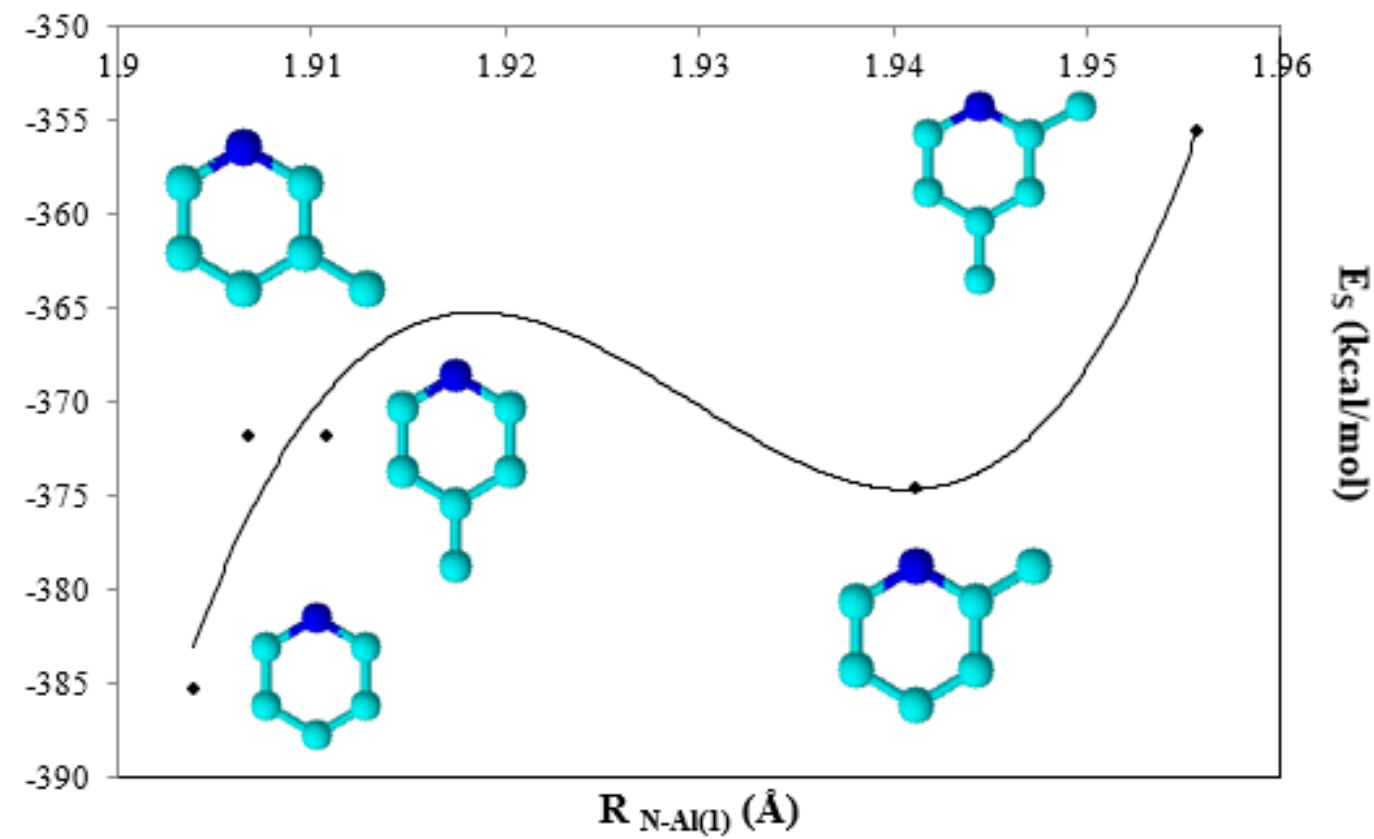

Figure 8. Calculated stabilization energies (Es) versus bond length between nitrogen atoms and Al (1), R N-Al(1) $(\AA)$, on co-adsorption model with a hydrogen atom and $\mathrm{Cl}^{-}$anion for pyridine and four derivatives of 2-picoline, 3-picoline, 4-picoline, and 2,4-lutidine.

In this way, the molecule of pyridine is directed to the sheet in doing a single rotation with a carbon-carbon double bond above a single platinum element. It has been discussed that $\mathrm{C} 2-\mathrm{Pt} \pi$-bond is higher than the carbon-nitrogen to platinum $\pi$-bond.

\section{Conclusions}

The adsorption, diffusion, and dissociation of pyridine, $\mathrm{C}_{5} \mathrm{H}_{5} \mathrm{~N}$, and four derivatives of 2-picoline, 3-picoline, 4-picoline, and 2,4-lutidine on $\mathrm{Al}(111)$-lattice have been investigated with density functional theory with LANL2DZ and 6-31G basis sets of theoretical level of gaussian 03 software. The potential energy of adsorption has been shown that pyridine 
molecule is adsorbed through the aromatic cycle directed to the sheet. In this way, pyridine and the molecules of its derivatives maintain jointed to the sheet in acting the rotation movement by a carbon-carbon double bond on a single aluminum element.

The computations are applied to discover the past practical results from the introduction for pyridine molecule and its organic derivatives on $\mathrm{Al}$ (111)-lattice.

The characteristics of the protonated molecules of pyridine and its derivatives compounds depend on the electronic charges and also the $\pi$ charge of the six-cycle. Pyridine and its derivatives have been adsorbed on the lattice of the Al electrode, mainly in their protonated forms. An adsorption template of the inhibitors can be possible, forming a junction between the nitrogen element and the molecule of the pyridine cycle near the element of the $\mathrm{Al}$ (111)-lattice in an inclined state.

\section{Funding}

This research received no external funding.

\section{Acknowledgments}

This research has no acknowledgment.

\section{Conflicts of Interest}

The authors declare no conflict of interest.

\section{References}

1. Fouda, A. S.; El-Desoky, H. S.; Abdel-Galeil M. A.; Mansour, D. Niclosamide and dichlorphenamide: new and effective corrosion inhibitors for carbon steel in 1M HCl solution. SN Applied Sciences 2021, 3, 287, https://doi.org/10.1007/s42452-021-04155-w.

2. Umoren, S.A.; Solomon, M.M. Polymeric Corrosion Inhibitors for Oil and Gas Industry. In Corrosion Inhibitors in the Oil and Gas Industry; Umoren, S.A., Saji, V.S., Eds.; Wiley: Hoboken, NJ, USA, 2020, 303320 .

3. Umoren, S.A.;Solomon, M.M.; Obot I.O.; and Suleiman, R.K. Effect of Intensifier Additives on the Performance of Butanolic Extract of Date Palm Leaves against the Corrosion of API 5L X60 Carbon Steel in 15 wt.\% HCl Solution. Sustainability 2021, 13, 5569, https://doi.org/10.3390/su13105569.

4. Odewunmi, N.A.; Moses M. Solomon, M.M.; Umoren, S.A.; and Ali, S.A. Comparative Studies of the Corrosion Inhibition Efficacy of a Dicationic Monomer and Its Polymer against API X60 Steel Corrosion in Simulated Acidizing Fluid under Static and Hydrodynamic Conditions. ACS Omega 2020, 5, 42, 27057 27071, https://doi.org/10.1021/acsomega.0c02345.

5. Caldona, E.B.; Zhang, M.; Liang, G.; Hollisa, T.K.; Webster, C.E.; Smith Jr, D.W.; Wipf, D.O.; Corrosion inhibition of mild steel in acidic medium by simple azole-based aromatic compounds. Journal of Electroanalytical Chemistry 2021, 880, 114858, https://doi.org/10.1016/j.jelechem.2020.114858.

6. Abd El-Lateef, H.M.Corrosion Inhibition Characteristics of a Novel Salycilidene Isatin Hydrazine Sodium Sulfonate on Carbon Steel in $\mathrm{HCl}$ and a Synergistic Nickel Ions Additive: A Combined Experimental and Theoretical Perspective. Appl. Surf. Sci. 2020, 501, 144237, https://doi.org/10.1016/j.apsusc.2019.144237.

7. Muthamma, K.; Kumari, P.; Lavanya, M.; Rao, S.A. Corrosion Inhibition of Mild Steel in Acidic Media by N-[(3,4-Dimethoxyphenyl)Methyleneamino]-4-Hydroxy-Benzamide,Journal of Bio- and Tribo-Corrosion 2021, 7, 10, https://doi.org/10.1007/s40735-020-00439-7.

8. Jessima, S.J.H.M.; Subhashini, S.; Berisha, A.; Oral, A.; Srikandan, S.S. Corrosion mitigation performance of disodium EDTA functionalized chitosan biomacromolecule-Experimental and theoretical approach. International Journal of Biological Macromolecules $\quad \mathbf{2 0 2 1}, \quad 178, \quad 477$ 491. https://doi.org/10.1016/j.ijbiomac.2021.02.166. 
9. Ricky, E.X.; Mpelwa, M.; Xu, X. The study of m-pentadecylphenol on the inhibition of mild steel corrosion in $1 \mathrm{M} \mathrm{HCl}$ solution. Journal of Industrial and Engineering Chemistry 2021, 20, https://doi.org/10.1016/j.jiec.2021.05.047.

10. Fouda, A.S.; Abd El-Ghaffar, M.A.; Sherif, M.H.; El-Habab, T.A.; El-Hossiany, A. Novel anionic 4-tertoctyl phenol ethoxylate phosphate surfactant as corrosion inhibitor for C-steel in acidic media. Prot Metals Phys Chem Surf 2020, 56, 189-201, https://doi.org/10.1134/S2070205120010086.

11. Mollaamin, F.; Monajjemi, M.; Salemi, S.; Baei, M.T. A Dielectric Effect on Normal Mode Analysis and Symmetry of BNNT Nanotube. FullerenesNanotubes and Carbon Nanostructure 2011, 19, 182-196, https://doi.org/10.1080/15363831003782932.

12. Yang, H.-M. Role of Organic and Eco-Friendly Inhibitors on the Corrosion Mitigation of Steel in Acidic Environments- A State-of-Art Review. Molecules 2021, 26, 3473, https://doi.org/10.3390/molecules26113473.

13. Kumar, H.; Yadav,V. Highly efficient and eco-friendly corrosion inhibitor for mild steel in $5 \mathrm{M} \mathrm{HCl}$ : An antipitting and anti-cracking agent. Chem. Data Collect. 2020, 30, 100552, https://doi.org/10.1016/j.cdc.2020.100552.

14. Addi, B.; Addi, A.; Shaban, A.; Habib, E.; Ait Addi, E.H.; Hamdani, M. Tincorrosioninhibitionby molybdate ions in $0.2 \mathrm{M}$ maleic acid solution: Electrochemical and surface analytical study. Mediterranean Journal of Chemistry 2020, 10, 465-476, http://dx.doi.org/10.13171/mjc10502005141394aa.

15. Ouakki, M.; Galai, M.; Rbaa, M.; Abousalem, A.S.; Lakhrissi, B.; Touhami, M.E.; Cherkaoui, M. Electrochemical, thermodynamic and theoretical studies of some imidazole derivatives compounds as acid corrosion inhibitors for mild steel. Journal of Molecular Liquids 2020, 319, https://doi.org/10.1016/j.molliq.2020.114063.

16. Al-Nami, S. Corrosion Inhibition Effect and Adsorption Activities of methanolic myrrh extract for $\mathrm{Cu}$ in 2 $\mathrm{M}$ HNO3. International Journal of Electrochemical Science 2020, 15, 1187-1205, https://doi.org/10.20964/2020.02.23.

17. Saraswat, V.; Yadav, M.; Obot, I. Investigations on eco-friendly corrosion inhibitors for mild steel in acid environment: Electrochemical, DFT and Monte Carlo Simulation approach. Colloids Surf. A Physicochem. Eng. Asp. 2020, 599, 124881, https://doi.org/10.1016/j.colsurfa.2020.124881.

18. Xiao, L.; Jianxin, P.; Jianren, Z.; Yafei, M.; Cai. C.S. Comparative assessment of mechanical properties of HPS between electrochemical corrosion and spray corrosion. Construction and Building Materials 2020, 237, https://doi.org/10.1016/j.conbuildmat.2019.117735.

19. Qiang, L.X.; Shijin, C.; Jiahong, H. Papaya leaves extract as a novel eco-friendly corrosion inhibitor for $\mathrm{Cu}$ in H2SO4 medium. Journal of Colloid and Interface Science 2020, 582, 918-931, https://doi.org/10.1016/j.jcis.2020.08.093.

20. Zhu, H.; Huo, Y.; Wang, W.; He, X.; Fang, S.; Zhang, Y. Quantum chemical calculation of reaction characteristics of hydroxyl at different positions during coal spontaneous combustion. Process Safety and Environmental Protection 2021, 148, 624-635, https://doi.org/10.1016/j.psep.2020.11.041.

21. Abdel Hameed, R.S.; Aljohani, M.M.; Essa, A.B.; 1, Khaled, A.; Nassar, A.M.; Badr, M.M.; Al-Mhyawi, S.R.; Soliman, M.S. Electrochemical Techniques for Evaluation of Expired Megavit Drugs as Corrosion Inhibitor for Steel in Hydrochloric Acid, Int. J. Electrochem. Sci. 2021, 16 , 210446, https://doi.org/10.20964/2021.04.15.

22. Khaleghian, M.; Zahmatkesh, M.; Mollaamin, F.; Monajjemi, M. Investigation of Solvent Effects on Armchair Single-Walled Carbon Nanotubes: A QM/MD Study. Fullerenes Nanotubes and Carbon Nanostructures 2011, 19, 4, https://doi.org/10.1080/15363831003721757.

23. Qiu, J.; Li, Y.; Xu, Y.; Wu, A.; Macdonald, D.D. Effect of temperature on corrosion of carbon steel in simulated concrete pore solution under anoxic conditions. Corros. Sci. 2020, 175, https://doi.org/10.1016/j.corsci.2020.108886.

24. Eid, A.M.; Shaaban, S.; Shalabi, K. Tetrazole-based organoselenium bi-functionalized corrosion inhibitors during oil well acidizing: Experimental, computational studies, and SRB bioassay. Journal of Molecular Liquids 2020, 298, https://doi.org/10.1016/j.molliq.2019.111980.

25. Sarasia, E.M.; Afsharnezhad, S.; Honarparvar, B.; Mollaamin, F.; Monajjemi, M. Theoretical study of solvent effect on NMR shielding tensors of luciferin derivatives. PCL 2011, 49, 561-571, https://doi.org/10.1080/00319101003698992. 
26. Aslam, J.; Aslam, R.; Lone, I.H.; Radwan, N.R.; Mobin, M.; Aslam, A.; Alzulaibani, A.A. Inhibitory effect of 2-Nitroacridone on corrosion of low carbon steel in $1 \mathrm{M} \mathrm{HCl}$ solution: An experimental and theoretical approach. Journal of Materials Research and Technology 2020, 9, 4061-4075, https://doi.org/10.1016/j.jmrt.2020.02.033.

27. Monajjemi, M.; Mahdavian, L.; Mollaamin, F.; Khaleghian, M. Interaction of Na, Mg, Al, Si with carbon nanotube (CNT): NMR and IR study. Russian Journal of Inorganic Chemistry 2009, 54, 1465-1473, https://doi.org/10.1134/S0036023609090216.

28. Chafiq, M.; Chaouiki,A.; Al-Hadeethi,M.R.; Ali,I.H.; Mohamed ,S.K.; Toumiat,K.; Salghi, R. NaproxenBased Hydrazones as Effective Corrosion Inhibitors for Mild Steel in 1.0 M HCl. Coatings 2020, 10, 700, https://doi.org/10.3390/coatings10070700.

29. Ghalandari, B.; Monajjemi, M.; Mollaamin, F. Theoretical Investigation of Carbon Nanotube Binding to DNA in View of Drug Delivery. J.Comput.Theor.Nanosci 2011, 8, 1212-1219, https://doi.org/10.1166/jctn.2011.1801.

30. Maeyoshi, Y.; Ding, D.; Kubota, M.; Ueda, H.; Abe, K.; Kanamura, K.; Abe, H. Long-term stable lithium metal anode in highly concentrated sulfolane-based electrolytes with ultrafine porous polyimide separator. ACS Appl. Mater. Interfaces 2019, 11, 25833-25843, https://doi.org/10.1021/acsami.9b05257.

31. Monajjemi, M.; Baie, M.T.; Mollaamin, F. Interaction between threonine and cadmium cation in $[\mathrm{Cd}(\mathrm{Thr}) \mathrm{n}$ 12+ ( $\mathrm{n}=1-3)$ complexes: density functional calculations, Russian Chemical Bulletin 2010, 59, 886-889, https://doi.org/10.1007/s11172-010-0181-5.

32. Qiang, Y.; Guo, L.; Li, H.; Lan, X. Fabrication of environmentally friendly Losartan potassium film for corrosion inhibition of mild steel in $\mathrm{HCl}$ medium. Chem. Eng. J. 2021, 406, 126863, https://doi.org/10.1016/j.cej.2020.126863.

33. Xiao, L.; Jianxin, P.; Jianren, Z.; Yafei, M.; Cai. C.S. Comparative assessment of mechanical properties of HPS between electrochemical corrosion and spray corrosion. Construction and Building Materials 2020, 237, https://doi.org/10.1016/j.conbuildmat.2019.117735.

34. Cui, M.; Qiang, Y.; Wang, W.; Zhao, H.; Ren, S. Microwave Synthesis of Eco-friendly Nitrogen Doped Carbon Dots for the Corro-sion Inhibition of Q235 Carbon Steel in 0.1 M HCl. Int. J. Electrochem. Sci. 2021, 16, 151019, https://doi.org/10.20964/2021.01.47.

35. Monajjemi, M.; Noei, M.; Mollaamin, F. Design of fMet-tRNA and calculation of its bonding properties by quantum mechanics. Nucleosides, Nucleotides and Nucleic Acids 2010, 29, 9, https://doi.org/10.1080/15257771003781642.

36. El Basiony, N.M.; Badr, E.E.; Baker, S.A.; El-Tabei, A.S. Experimental and theoretical (DFT\&MC) studies for the adsorption of the synthesized Gemini cationic surfactant based on hydrazide moiety as X-65 steel acid corrosion inhibitor. Appl. Surf. Sci. 2021, 539, 148246, https://doi.org/10.1016/j.apsusc.2020.148246.

37. Monajjemi, M.; Mollaamin, F.; Gholami, M.R.; Yoosbashizadeh, H.; Sadrnezhad, S.K.; Passdar, H. Quantum Chemical Parameters of Some Organic Corrosion Inhibitors, Pyridine, 2-Picoline 4-Picoline and 2, 4Lutidine, Adsorption at Aluminum Surface in Hydrocholoric and Nitric Acids and Comparison Between Two Acidic Media. Main Group Met. Chem. 2003, 26, 349-362, https://doi.org/10.1515/MGMC.2003.26.6.349.

38. Cui, M.; Yu, Y.; Zheng, Y. Effective Corrosion Inhibition of Carbon Steel in Hydrochloric Acid by Dopamine-Produced Carbon Dots. Polymers 2021, 13, 1923, https://doi.org/10.3390/polym13121923.

39. Kaneko, T.; Sodeyama, K. FiKrst-principles molecular dynamics study for SO bond dissociation of sulfolane on Li-metal negative electrode. Chemical Physics Letters 2021, 762, 138199, https://doi.org/10.1016/j.cplett.2020.138199.

40. Lee, V.S.; Nimmanpipug, P.; Mollaamin, F.; Kungwan, N.; Thanasanvorakun, S.; Monajjemi, M. Investigation of single wall carbon nanotubes electrical properties and normal mode analysis: Dielectric effects. Russian Journal of Physical Chemistry A 2009, 83, 2288-2296, https://doi.org/10.1134/S0036024409130184.

41. Nakanishi, A.; Ueno, K.; Watanabe, D.; Ugata, Y.; Matsumae, Y.; Liu, J.; Thomas, M.L.; Dokko, K.; Watanabe, M. Sulfolane-based highly concentrated electrolytes of Lithium Bis(trifluoromethanesulfonyl)amide: Ionic transport, Li-Ion coordination, and Li-S battery performance.J. Phys. Chem. C. 2019, 123, 14229 14238, https://doi.org/10.1021/acs.jpcc.9b02625.

42. Monajjemi, M.; Farahani, N.; Mollaamin, F. Thermodynamic study of solvent effects on nanostructures: phosphatidylserine and phosphatidylinositol membranes. PCL 2012, 50, 161-172, https://doi.org/10.1080/00319104.2010.527842. 
43. Al-Baghdadi,S.; Gaaz,T.S.; Al-Adili, A.; Al-Amiery,A.A.; Takriff, M.S.; Experimental studies on corrosion inhibition performance of acetylthiophene thiosemicarbazone for mild steel in $\mathrm{HCl}$ complemented with DFT investigation. International Journal of Low-Carbon Technologies 2021, $16 \quad$ 181-188, https://doi.org/10.1093/ijlct/ctaa050.

44. Bakhshi, K.; Mollaamin, F.; Monajjemi, M. Exchange and Correlation Effect of Hydrogen Chemisorption on Nano V(100) Surface: A DFT Study by Generalized Gradient Approximation (GGA). Journal of Computational and Theoretical Nanoscience 2011, 8, 763-768, https://doi.org/10.1166/jctn.2011.1750.

45. Ayoola, A.A.; Auta-Joshua, N.; Durodola, B.M.; Omodara, O.J.; Oyeniyi, E.A. Combating A36 mild steel corrosion in $1 \mathrm{M} \mathrm{H}_{2} \mathrm{SO}_{4}$ medium using watermelon seed oil inhibitor. AIMS Materials Science 2021, 8, 130143, https://doi.org/10.3934/matersci.2021009.

46. Ye, Y.; Zou, Y.; Jiang, Z.; Yang, Q.; Chen, L.; Guo, S.; Chen, H. An effective corrosion inhibitor of N doped carbon dots for Q235 steel in $1 \mathrm{M} \mathrm{HCl}$ solution. J. Alloys Compd. 2020, 815, 152338, https://doi.org/10.1016/j.jallcom.2019.152338.

47. Tahan, A.; Mollaamin, F.; Monajjemi, M. Thermochemistry and NBO analysis of peptide bond: Investigation of basis sets and binding energy. Russian Journal of Physical Chemistry A 2009, 83, 587-597, https://doi.org/10.1134/S003602440904013X.

48. Bedir,A.G.; El-raouf, M.A.;Abdel-Mawgoud,S.; Negm,N.A.; and El Basiony,N.M. Corrosion Inhibition of Carbon Steel in Hydrochloric Acid Solution Using Ethoxylated Nonionic Surfactants Based on Schiff Base: Electrochemical and Computational Investigations. ACS Omega 2021, $6 \quad, \quad 4300-4312$, https://doi.org/10.1021/acsomega.0c05476.

49. M.J.Frisch, et al. Gaussian 03, revision C. 02; Gaussian, Inc.: Wallingford, CT (2004).

50. Ouakki, M.; Galai, M.; Rbaa, M.; Abousalem, A.S.; Lakhrissi, B.; Touhami, M.E.; Cherkaoui, M. Electrochemical, thermodynamic and theoretical studies of some imidazole derivatives compounds as acid corrosion inhibitors for mild steel. Journal of Molecular Liquids 2020, 319, https://doi.org/10.1016/j.molliq.2020.114063.

51. Monajjemi, M.; Afsharnezhad, S.; Jaafari, M.R.; Mirdamadi, S.; Mollaamin, F.; Monajemi, H. Investigation of energy and NMR isotropic shift on the internal rotation Barrier of $\Theta 4$ dihedral angle of the DLPC: A GIAO study. Chemistry 2008, 17, 1. 